\title{
The Effect of Impinging Jet on the Flow and Heat Transfer from Isothermal Moving Plate
}

\author{
Dr. Ahmed Waheed Mustafa
}

\author{
Lecturer \\ University of Tikrit-Engineering College-Mechanical Engineering Department
}

\begin{abstract}
The effect of impinging uniform jet on flow and heat transfer over isothermal moving plate is investigated. The flow and temperature fields are studied numerically with different jet velocity ratio (jet to plate velocity ratio $0-5$ ). The laminar flow field is analyzed numerically by solving the steady, two-dimensional incompressible NavierStokes and energy equations. A collocated (non-staggered) grid is used in the momentum equations, which discretized by finite volume method, SIMPLE algorithm is used to adjust the velocity field to satisfy the conservation of mass. The range of Reynolds number is $(\operatorname{Re}=10-100)$. The results show that at high jet velocity ratio (V/U $=5)$ and Reynolds number $(\operatorname{Re}=100)$, the rate of heat transfer from the plate is doubled.
\end{abstract}

Keywords: Moving Plate, Impinging Jet, Finite Volume, Collocated Grid

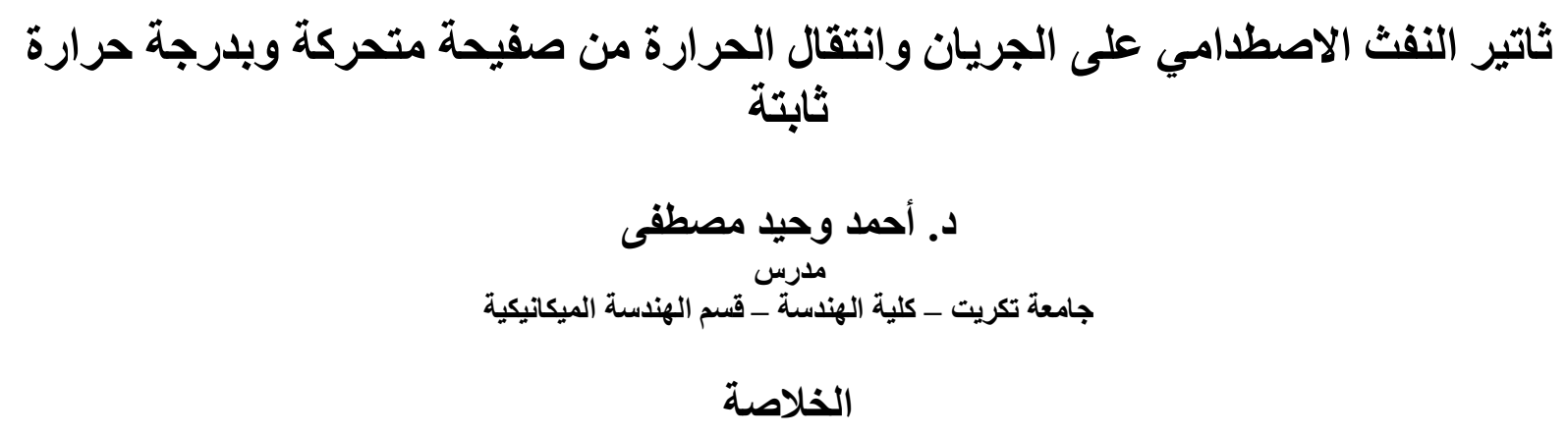

ثاثير النفث الاصطدامي المنتظم على الجريان وانتقال الحرارة من صفيحة متحركة بلدرجة الحرارة ثابتة تمت دراستة دراستة.

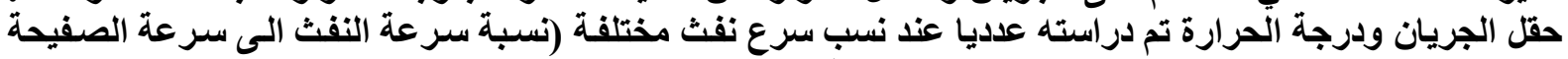

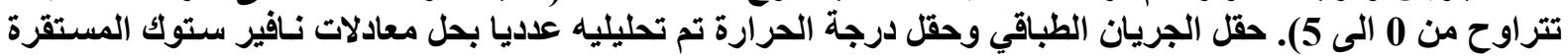

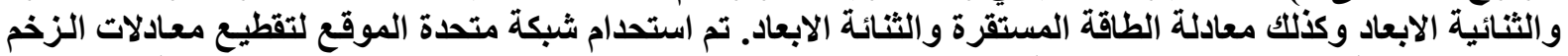

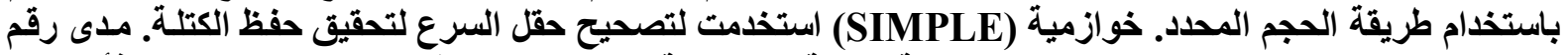
رينولا هو (10-100) ـ بينت النتائج انه عند نسبة سرعة نفث عالية (V/U =5) ورقم رينولا (Re =100) فأن معدل

انتقال الحرارة من الصفيحة يتضاعف. 


\section{Nomenclature}

F mass flux

L Length of the plate

$\mathrm{Nu}$ Average Nusselt number

P Dimensionless Pressure

Re Reynolds number

U Dimensionless plate velocity

V Dimensionless jet velocity

$X$ Dimensionless axial coordinate

Y Dimensionless vertical coordinate

\section{Subscripts}

e East face of the control volume

$n$ North face of the control volume

s South face of the control volume

w West face of the control volume

Superscripts

* Old value

' Corrected Value

\section{Introduction}

A continuously moving surface through an otherwise quiescent medium has many applications in manufacturing processes. Such processes are hot rolling, wire drawing, metal extrusion, crystal growing, continuous casting, glass fiber production, and paper production Altan et al., [1], Fisher, [2], Tadmor and Klein, [3]. The study of Flow Field and heat transfer is necessary for determining the quality of the Final products of such processes as explained by Karwe and Jaluria [4] and [5].

In almost all the papers cited earlier, the studies concentrated on the boundary layer far away from the extrusion slit where the boundary layer approximations and, hence, the similarity method are valid. However, in most practical applications, the flow and heat-transfer characteristics are very important close to the slit at which both the friction and heat transfer coefficients attain their largest values. On the other hand, the finite- difference method using the full governing equations was used by Karwe and Jaluria [4] and [5], for uniformly moving flat plate with a uniform temperature at the slit, to study the effects near the slit from which the plate emerges. Furthermore, Kang and Jaluria [6] included the buoyancy effects on moving plate in materials processing. In these papers, the effect of jet on the moving plate was not included. However, during the manufacture of some materials such as continuous casting it is often necessary to cool the moving material Jaluria [7]. The present study focuses on the effect of impinging jet on the moving surface using the full governing equations.

\section{Mathematical Model}

Figure 1 shows a continuously moving plate emerges from a slit at a dimensionless velocity $U=1$ and a dimensionless temperature $\theta=1$. The motion of the fluid is assumed to be laminar, steady, and two dimensional with thermal active incompressible viscous fluid with constant properties. Subject to these assumptions the governing equations in dimensionless form can be written as:

$$
\begin{aligned}
& \frac{\partial U}{\partial X}+\frac{\partial V}{\partial Y}=0 \\
& \frac{\partial\left(U^{2}\right)}{\partial X}+\frac{\partial(U V)}{\partial Y}=-\frac{\partial P}{\partial X}+\frac{1}{\operatorname{Re}}\left(\frac{\partial^{2} U}{\partial X^{2}}+\frac{\partial^{2} U}{\partial Y^{2}}\right) \\
& \frac{\partial(U V)}{\partial X}+\frac{\partial\left(V^{2}\right)}{\partial Y}=-\frac{\partial P}{\partial Y}+\frac{1}{\operatorname{Re}}\left(\frac{\partial^{2} V}{\partial X^{2}}+\frac{\partial^{2} V}{\partial Y^{2}}\right) \\
& \frac{\partial(U \theta)}{\partial X}+\frac{\partial(V \theta)}{\partial Y}=\frac{1}{\operatorname{Re} \operatorname{Pr}}\left(\frac{\partial^{2} \theta}{\partial X^{2}}+\frac{\partial^{2} \theta}{\partial Y^{2}}\right) \\
& \text { Where } \\
& U=u / U_{\text {Plate }}, V=v / U_{\text {Plate }}, \operatorname{Re}=\frac{U_{\text {Plate }} L}{v}, \operatorname{Pr}=\frac{v}{\alpha}, \theta=\frac{T-T_{\infty}}{T_{W}-T_{\infty}}, P=\frac{p}{\rho U_{\text {Plate }}^{2}}
\end{aligned}
$$




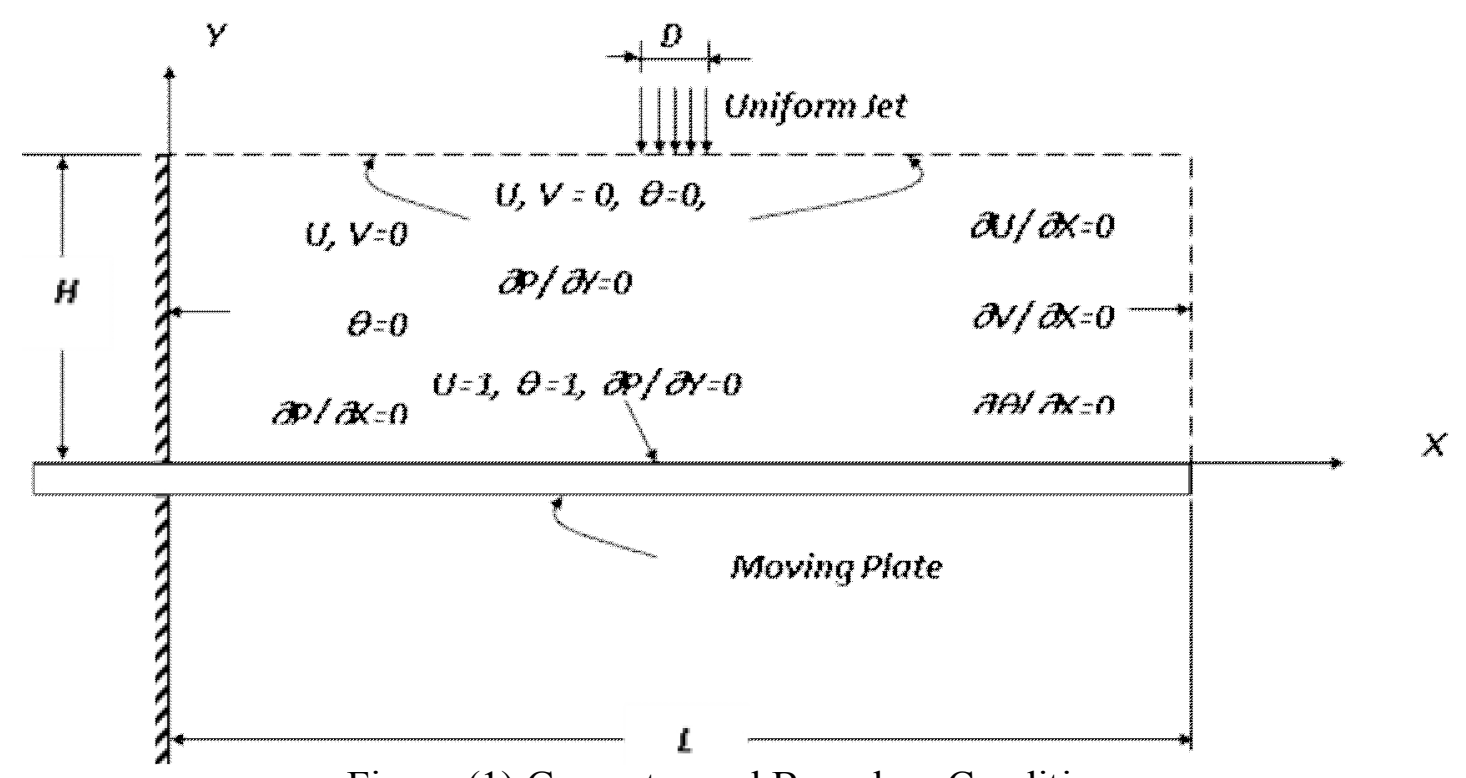

Figure (1) Geometry and Boundary Conditions

\section{Boundary Conditions}

The boundary conditions used in numerical solution are illustrated in figure 1. A uniform impinging jet of thickness (D) is assumed.

\section{Discretization of the Governing Equations}

The governing equations are discretized by using the finite volume method based on nonstaggered (collocated) grid. Since all variables are stored in the center of the control volume, the interpolation method is used to avoid the decoupling between velocity and pressure; this interpolation method is presented in this paper.

The continuity and the momentum equations are discretized over the collocated gird shown in figure 2 . By integrating the $\mathrm{x}$ momentum equation (2) over the control volume shown in figure (2), we have

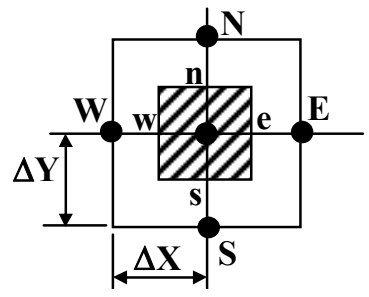

Figure (2) Control

$$
\int \frac{\partial}{\partial X}(U U) d X d Y+\int \frac{\partial}{\partial Y}(U V) d X d Y=-\int \frac{\partial P}{\partial X} d X d Y+\frac{1}{\mathrm{Re}} \int \frac{\partial^{2} U}{\partial X^{2}} d X d Y+\frac{1}{\mathrm{Re}} \int \frac{\text { Volume }}{\partial Y^{2}} d X d Y
$$

$$
[U U \Delta Y]_{w}^{e}+[U V \Delta X]_{s}^{n}=-\left(P_{e}-P_{w}\right) \Delta Y+\frac{1}{\operatorname{Re}}\left[\frac{\partial U}{\partial X} \Delta Y\right]_{w}^{e}+\frac{1}{\operatorname{Re}}\left[\frac{\partial U}{\partial Y} \Delta X\right]_{s}^{n}
$$

For numerical stability, the convection term (left side of equation 6) are approximated by the upwind differencing scheme, Patankar [8] as

$[U U \Delta Y]_{w}^{e}=U_{e} F_{e}-U_{w} F_{w}=\left[U_{P} \max \left(F_{e}, 0\right)-U_{E} \max \left(-F_{e}, 0\right)\right]-\left[U_{W} \max \left(F_{w}, 0\right)-U_{P} \max \left(-F_{w}, 0\right)\right]$

Where $F_{e}=(U \Delta Y)_{e}, F_{w}=(U \Delta Y)_{w}$, are the mass flux at the control volume faces $e$ and $w$ respectively.

By the same scheme the second convective term can be approximated as

$[U V \Delta Y]_{s}^{n}=U_{n} F_{n}-U_{s} F_{s}=\left[U_{P} \max \left(F_{n}, 0\right)-U_{N} \max \left(-F_{n}, 0\right)\right]-\left[U_{S} \max \left(F_{s}, 0\right)-U_{P} \max \left(-F_{s}, 0\right)\right]$

Where $F_{n}=(V \Delta X)_{n}, F_{s}=(V \Delta X)_{s}$, are the mass flux at the control volume faces $n$ and $s$ respectively. 
The diffusion terms can be approximated by the center difference as

$\frac{1}{\operatorname{Re}}\left[\frac{\partial U}{\partial X} \Delta Y\right]_{w}^{e}=D_{e}\left(U_{E}-U_{P}\right)-D_{w}\left(U_{P}-U_{W}\right)$

Where $D_{e}=\left(\frac{\Delta Y}{\operatorname{Re} \Delta X}\right)_{e}, D_{w}=\left(\frac{\Delta Y}{\operatorname{Re} \Delta X}\right)_{w}$

$\frac{1}{\operatorname{Re}}\left[\frac{\partial U}{\partial Y} \Delta X\right]_{s}^{n}=D_{n}\left(U_{N}-U_{P}\right)-D_{s}\left(U_{P}-U_{S}\right)$

Where $D_{n}=\left(\frac{\Delta X}{\operatorname{Re} \Delta Y}\right)_{n}, D_{s}=\left(\frac{\Delta X}{\operatorname{Re} \Delta Y}\right)_{s}$

Substituting of equs.(7),(8),(9), and (10) into equ.(6) gives:-

$a_{P} U_{P}=\sum_{n b} a_{n b} U_{n b}+\left(1-\alpha_{U}\right) a_{P} U_{P}^{0}-\left(P_{e}-P_{w}\right) \Delta Y$

Where the index $(n b)$ runs over all neighboring points $E, W, N$, and $S$, and

$a_{E}=D_{e}+\max \left(-F_{e}, 0\right)$

$a_{W}=D_{w}+\max \left(F_{w}, 0\right)$

$a_{N}=D_{n}+\max \left(-F_{n}, 0\right)$

$a_{S}=D_{s}+\max \left(F_{s}, 0\right)$

$a_{P}=\sum_{n b} a_{n b} / \alpha_{U}$

Where $\left(\alpha_{U}\right)$ is the under-relaxation parameter, necessary for stability, Patankar [8]. The quantity $U_{P}{ }^{0}$ in equation (11) indicates the value of $U_{P}$ from the previous iteration. For the collocated arrangement, the coefficients in equs. (12a-e) are same for $V$-equation. For the energy ( $\theta$-equation) the coefficients in equs. (12a-e) are same except $(1 / \mathrm{Re})$ in diffusion coefficients $\left(D_{e}, D_{w}, D_{n}\right.$ and $\left.D_{s}\right)$ is replaced by $(1 / \operatorname{RePr})$.

\section{Pressure-Velocity Coupling}

The $U$ - and $V$ - momentum equations are solved using guessed values for the pressure field and mass fluxes. The velocity components $U^{*}$ and $V^{*}$, calculated with these guessed values will not satisfy the continuity equation, so that the velocity components must be corrected as

$U=U^{\prime}+U^{*}$

$V=V^{\prime}+V^{*}$

Where $U^{\prime}$, and $V^{\prime}$ are corrected velocities and can be calculated as follows:-

Rewrite the $U$-equation (equ. 11$)$ for node $(P)$ and $(E)$ (see figure 2 ) as: 


$$
\begin{aligned}
U_{P}^{*} & =\left(\frac{\sum_{n b} a_{n b} U_{n b}^{*}+\left(1-\alpha_{U}\right) a_{P} U_{P}^{0}-\left(P_{e}^{*}-P_{w}^{*}\right) \Delta Y}{a_{P}}\right)_{P} \\
U_{E}^{*} & =\left(\frac{\sum_{n b} a_{n b} U_{n b}^{*}+\left(1-\alpha_{U}\right) a_{P} U_{P}^{0}-\left(P_{e}^{*}-P_{w}^{*}\right) \Delta Y}{a_{P}}\right)_{E}
\end{aligned}
$$

To find $u_{e}^{*}$ at east face of the control volume (figure 2), we use linear interpolation except the pressure term which is calculated as in the staggered approach, Rhie and Chow [9].

$u_{e}^{*}=\overline{\widehat{u}_{e}^{*}}-\overline{\left(\frac{1}{a_{P}}\right)_{e}}(\Delta Y)_{e}\left(P_{E}^{*}-P_{P}^{*}\right)$

Where

$\overline{\widehat{u}_{e}^{*}}=\overline{\left(\frac{\sum_{n b} a_{n b} U_{n b}^{*}+\left(1-\alpha_{U}\right) a_{P} U_{P}^{0}}{a_{P}}\right)_{e}}$

Where the overbar indicates linear interpolation. By the same method we can find the velocities at ( $\mathrm{w}, \mathrm{n}$, and $\mathrm{s})$ faces as

$$
\begin{aligned}
& u_{w}^{*}=\overline{\widehat{u}_{w}^{*}}-\overline{\left(\frac{1}{a_{P}}\right)_{w}}(\Delta Y)_{w}\left(P_{P}^{*}-P_{W}^{*}\right) \\
& v_{n}^{*}=\overline{\widehat{v}_{n}^{*}}-\overline{\left(\frac{1}{a_{P}}\right)_{n}}(\Delta X)_{n}\left(P_{N}^{*}-P_{P}^{*}\right) \\
& u_{s}^{*}=\overline{\widehat{v}_{s}^{*}}-\overline{\left(\frac{1}{a_{P}}\right)_{s}}(\Delta X)_{s}\left(P_{P}^{*}-P_{S}^{*}\right)
\end{aligned}
$$

To enforce mass conservation, velocity and pressure correction are introduced by Rhie and Chow [9]

$$
\begin{aligned}
& u_{e}^{\prime}=-\overline{\left(\frac{1}{a_{P}}\right)_{e}}(\Delta Y)_{e}\left(P_{E}^{\prime}-P_{P}^{\prime}\right) \\
& u_{w}^{\prime}=-\overline{\left(\frac{1}{a_{P}}\right)_{w}}(\Delta Y)_{w}\left(P_{P}^{\prime}-P_{W}^{\prime}\right) \\
& v_{n}^{\prime}=-\overline{\left(\frac{1}{a_{P}}\right)_{n}}(\Delta X)_{n}\left(P_{N}^{\prime}-P_{P}^{\prime}\right) \\
& v_{s}^{\prime}=-\left(\frac{1}{a_{P}}\right)_{s}(\Delta X)_{s}\left(P_{P}^{\prime}-P_{S}^{\prime}\right)
\end{aligned}
$$

The discretization of continuity equation is 
$\left(u_{e}-u_{w}\right) \Delta Y+\left(v_{n}-v_{s}\right) \Delta X=0$

To correct the velocities at the faces of the control volume:

$u_{e}=u_{e}^{*}+u_{e}^{\prime}$

$u_{w}=u_{w}^{*}+u_{w}^{\prime}$

$v_{n}=v_{n}^{*}+v_{n}^{\prime}$

$v_{s}=v_{s}^{*}+v_{s}^{\prime}$

Substituting equs.(26) into equ.(25) yields

$\left(u_{e}^{\prime}-u_{w}^{\prime}\right) \Delta Y+\left(v_{n}^{\prime}-v_{s}^{\prime}\right) \Delta X=\left(u_{e}^{*}-u_{w}^{*}\right) \Delta Y+\left(u_{n}^{*}-v_{s}^{*}\right) \Delta X$

Or

$\left(u_{e}^{\prime}-u_{w}^{\prime}\right) \Delta Y+\left(v_{n}^{\prime}-v_{s}^{\prime}\right) \Delta X=S_{P}$

Where $S_{P}$ is the mass source and is given by

$S_{P}=\left(u_{e}^{*}-u_{w}^{*}\right) \Delta Y+\left(u_{n}^{*}-v_{s}^{*}\right) \Delta X$

Substituting equs. $\left(21,22,23\right.$, and 24) into equ. (27) and assuming $(\Delta Y)_{e}=(\Delta Y)_{w}=\Delta Y$ and $(\Delta X)_{n}=(\Delta X)_{s}=\Delta X$, gives:-

$a_{P P} P_{P}^{\prime}=a_{E E} P_{E}^{\prime}+a_{W W} P_{W}^{\prime}+a_{N N} P_{N}^{\prime}+a_{S S} P_{S}^{\prime}+S_{P}$

Where

$a_{E E}=\overline{\left(\frac{1}{a_{P}}\right)_{e}} \Delta Y^{2}$

$a_{W W}=\overline{\left(\frac{1}{a_{P}}\right)_{w}} \Delta Y^{2}$

$a_{N N}=\overline{\left(\frac{1}{a_{P}}\right)_{n}} \Delta X^{2}$

$a_{S S}=\overline{\left(\frac{1}{a_{P}}\right)_{S}} \Delta X^{2}$

$a_{P P}=a_{E E}+a_{W W}+a_{N N}+a_{S S}$

\section{Solution Procedure}

For the steady and non-staggered (collocated), the overall SIMPLE solution procedure takes the following steps

(1) Guess the pressure field $\left(P^{*}\right)$.

(2) Calculate the coefficient of the momentum equations form equations (12). 
(3) Solve the $\left(U^{*}, V^{*}\right)$ momentum equation by line-by-line method of equation (11) using the guessed pressure field $\left(P^{*}\right)$.

(4) Compute the face mass flow rates $\left(F_{e}{ }^{*}, F_{w}{ }^{*}, F_{n}{ }^{*}\right.$, and $\left.F_{s}{ }^{*}\right)$ by using interpolated face velocities from equations $(16,18,19$, and 20$)$.

(5) Calculate the source term of the pressure correction equation from equation (28).

(6) Calculate the coefficients of the pressure correction equation from equations (30).

(7) Solve the pressure correction equation (29) by line-by-line method to obtain the corrected pressure field $\left(P^{\prime}\right)$.

(8) Calculate the correction of the velocities from equations $(21,22,23$, and 24).

(9) Calculate the correction of face mass flow rates $\left(F_{e}{ }^{\prime}, F_{w}{ }^{\prime}, F_{n}{ }^{\prime}\right.$, and $\left.F_{s}{ }^{\prime}\right)$ based on the corrected velocities calculated in step (8).

(10) Correct the velocities by using equations (13); and face mass flow rates by

$F_{e}=F_{e}{ }^{*}+F_{e}{ }^{\prime}$

$F_{w}=F_{w}{ }^{*}+F_{w}{ }^{\prime}$

$F_{n}=F_{n}{ }^{*}+F_{n}{ }^{\prime}$

$F_{s}=F_{s}^{*}+F_{s}{ }^{\prime}$

(11) Correct the control volumes pressure by underrelaxed the pressure correction as $\left(P=P^{*}+\alpha_{p} P^{\prime}\right)$

(12) Calculate the temperature field $(\theta)$ by solving the descritized energy equation.

Return to step 1 and repeat step 1 to 12 until the convergence is attained.

For each variable, the sum of the absolute value of the residuals over all the control volume is calculated, and normalized by an appropriate quantity $F_{n}$, typically the inlet mass or momentum flux, this normalized sum of the absolute residuals should be satisfies

$$
\frac{\sum_{k} R^{k}}{F_{n}} \leq \lambda
$$

Values of $\lambda$ used in calculations were of order $10^{-3}$.

\section{Grid Independence}

The table below shows the results of the average Nusselt number $\left(\mathrm{Nu}=\left.\int_{0}^{1} \frac{\partial \theta}{\partial Y}\right|_{Y=0} d Y\right)$ obtained for the grid independence study for the case $\mathrm{Re}=100$, and $\mathrm{V} / \mathrm{U}=5$. A grid size of $61 \mathrm{X} 31$ (61 in $\mathrm{X}$ direction and 31 in $\mathrm{Y}$ direction) gives a grid independence solution. 


\begin{tabular}{|c|c|}
\hline $\begin{array}{c}\text { Grid } \\
\text { Size(MXN) }\end{array}$ & $\begin{array}{c}\text { Average Nusselt } \\
\text { Number (Nu) }\end{array}$ \\
\hline $31 \times 21$ & 3.33 \\
\hline $41 \times 21$ & 3.98 \\
\hline $51 \times 21$ & 4.44 \\
\hline $51 X 21$ & 5.78 \\
\hline $61 \times 31$ & 6.006 \\
\hline $61 X 41$ & 6.0 \\
\hline
\end{tabular}

\section{Validation}

The numerical solution is validated by comparing results of the axial velocity at the trailing edge of the plate with the numerical results of Sami and Mohamed [1] for Reynolds number $(\mathrm{Re}=100)$, (There is no jet $\mathrm{V}=0)$. Figure 3 shows an excellent agreement between our results and the numerical results of Sami and Mohamed [10].

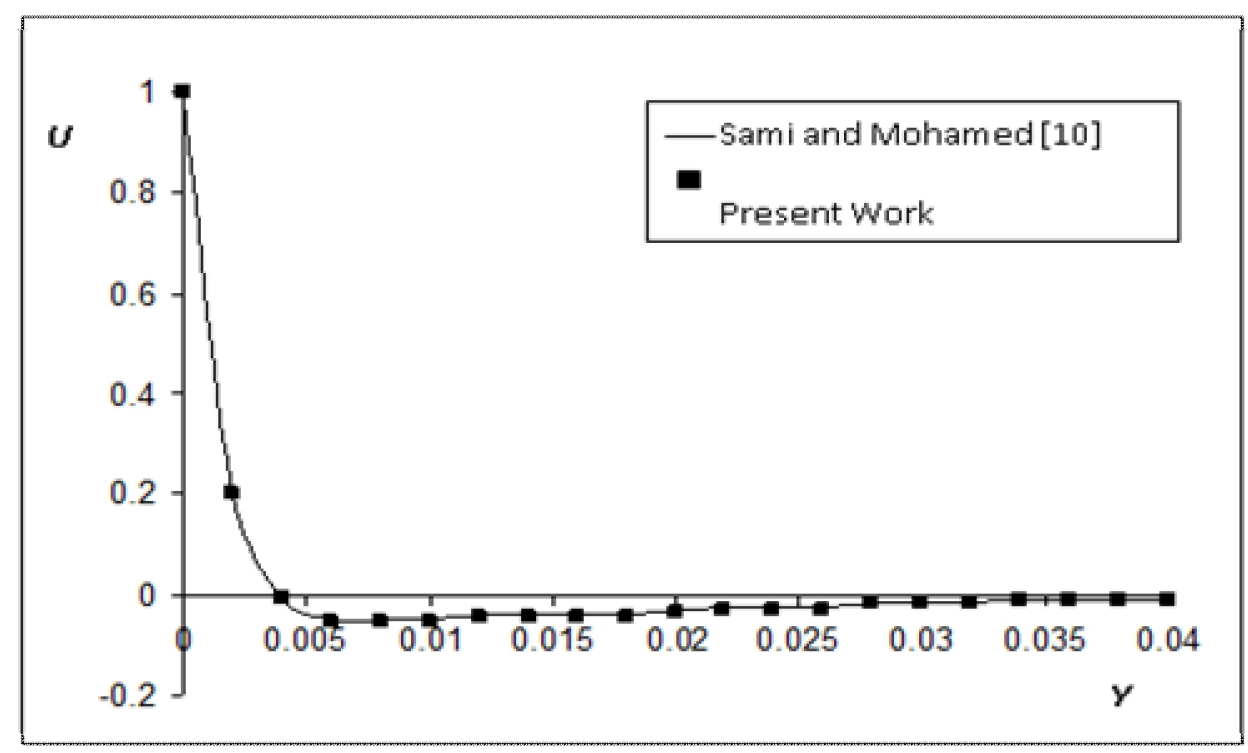

Figure (3) Comparison of the Axial Velocity at the trailing edge of the plate for $(\mathrm{Re}=100$, and $\mathrm{V} / \mathrm{U}=0)$.

\section{Results}

Four jet velocities $(\mathrm{V} / \mathrm{U}=0,1,3,5)$ are considered. The jet height $(\mathrm{H})$ is set to $0.5 \mathrm{~L}$. The jet thickened (D) is set $(1 / 6 \mathrm{~L})$. The Prandtl number is set to 0.7 .

In figure (4a-d, left) the contours of the predicted streamlines are shown for jet velocity ratio $(0,1,3$, and 5$)$ for Reynolds number $(\operatorname{Re}=10)$. As the jet velocity ratio increases while the velocity of the plate remain constant, at this low Reynolds number there is no effect from the jet on the isothermal lines as shown in figure (4a-d, right), so that the average Nusselt number remains constant as shown in figure (6).

In figure (5a-d, left) the contours of the predicted streamlines are shown for Reynolds number $(\operatorname{Re}=100)$ and for $(0,1,3$, and 5$)$. As the jet velocity ratio increases, and this high Reynolds number, the rate of heat transfer (Nusselt number) is doubled due to the increase of the temperature gradient below the jet as shown in figure (5b-d, right), which causes this increasing in heat transfer rate. 


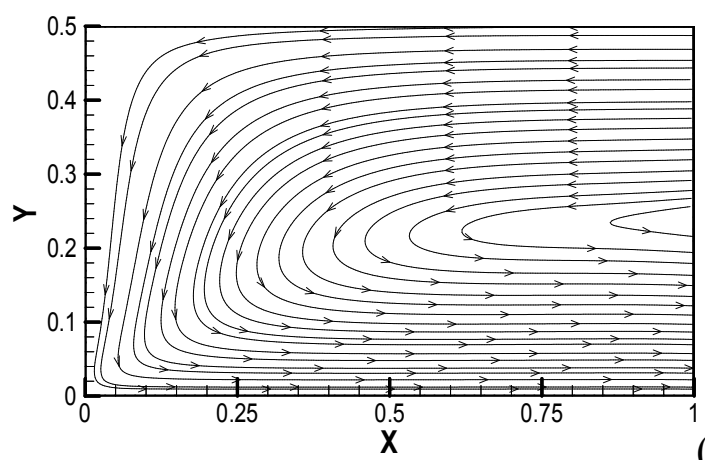

(a) $\mathrm{V} / \mathrm{U}=0$
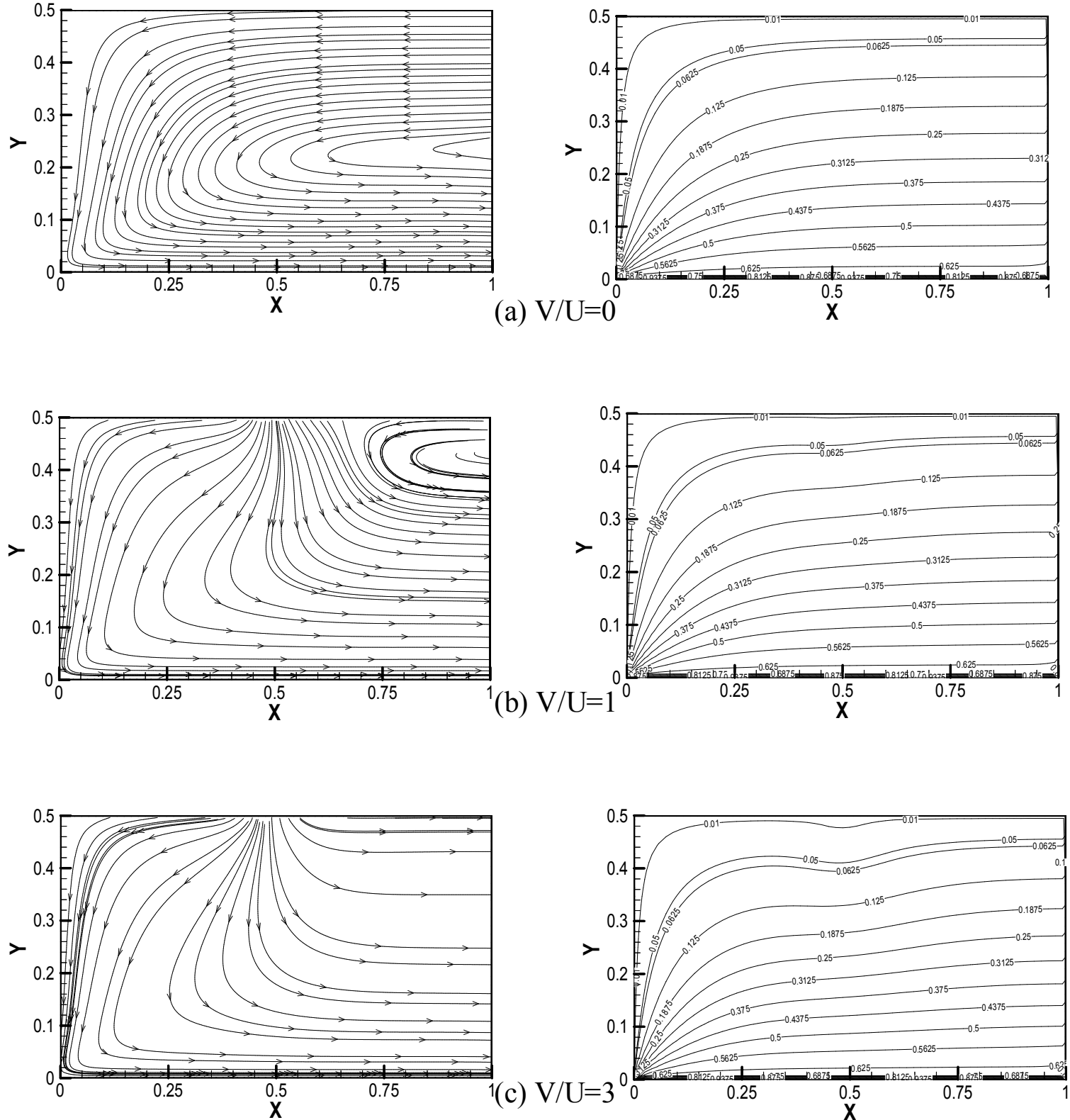

$1(\mathrm{c})$

(b) $\mathrm{V} / \mathrm{U}=1$
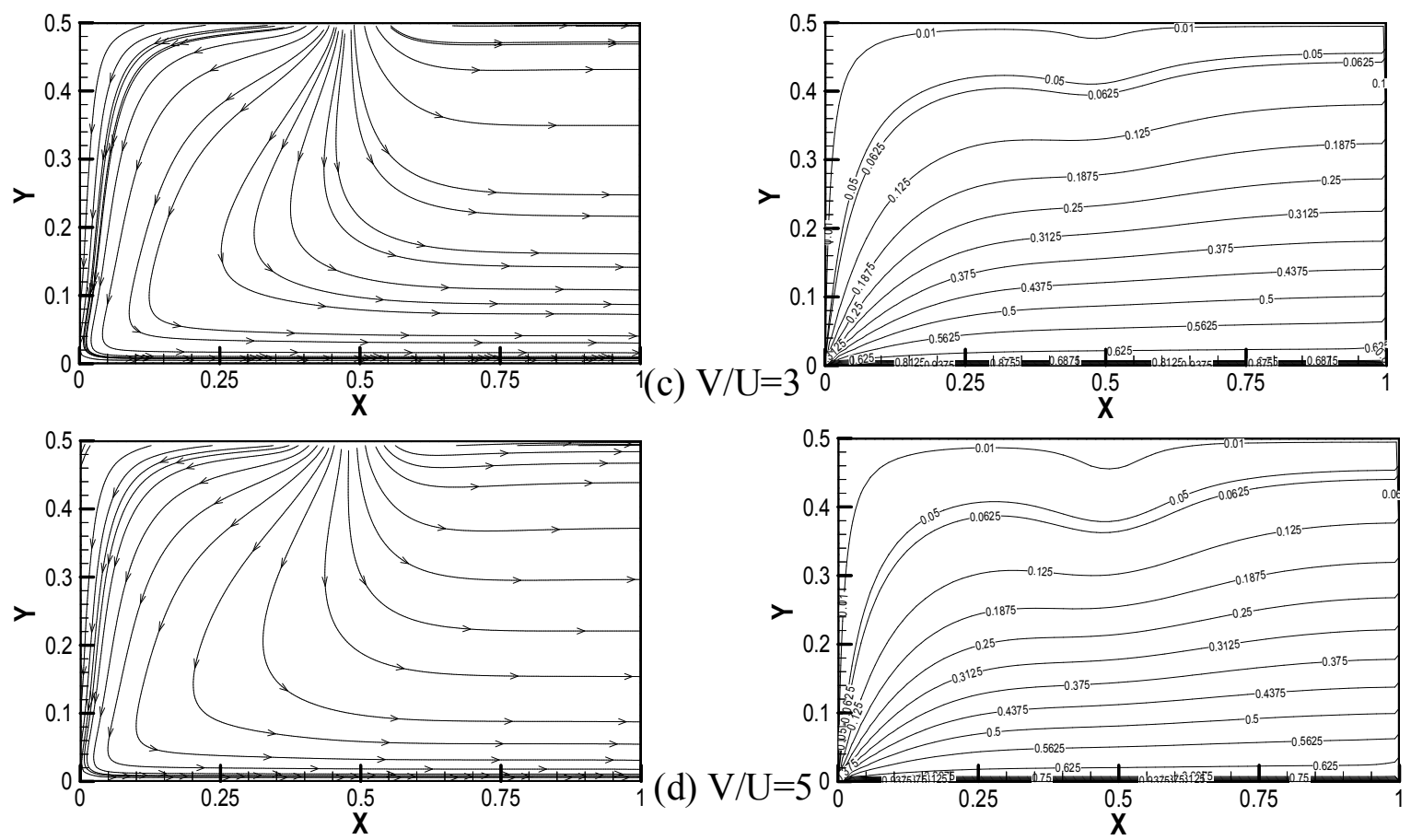

Figure (4) Streamlines (left), and Isotherms (right) contours at Different Jet Velocities for Reynolds Number $(\mathrm{Re}=10)$ 

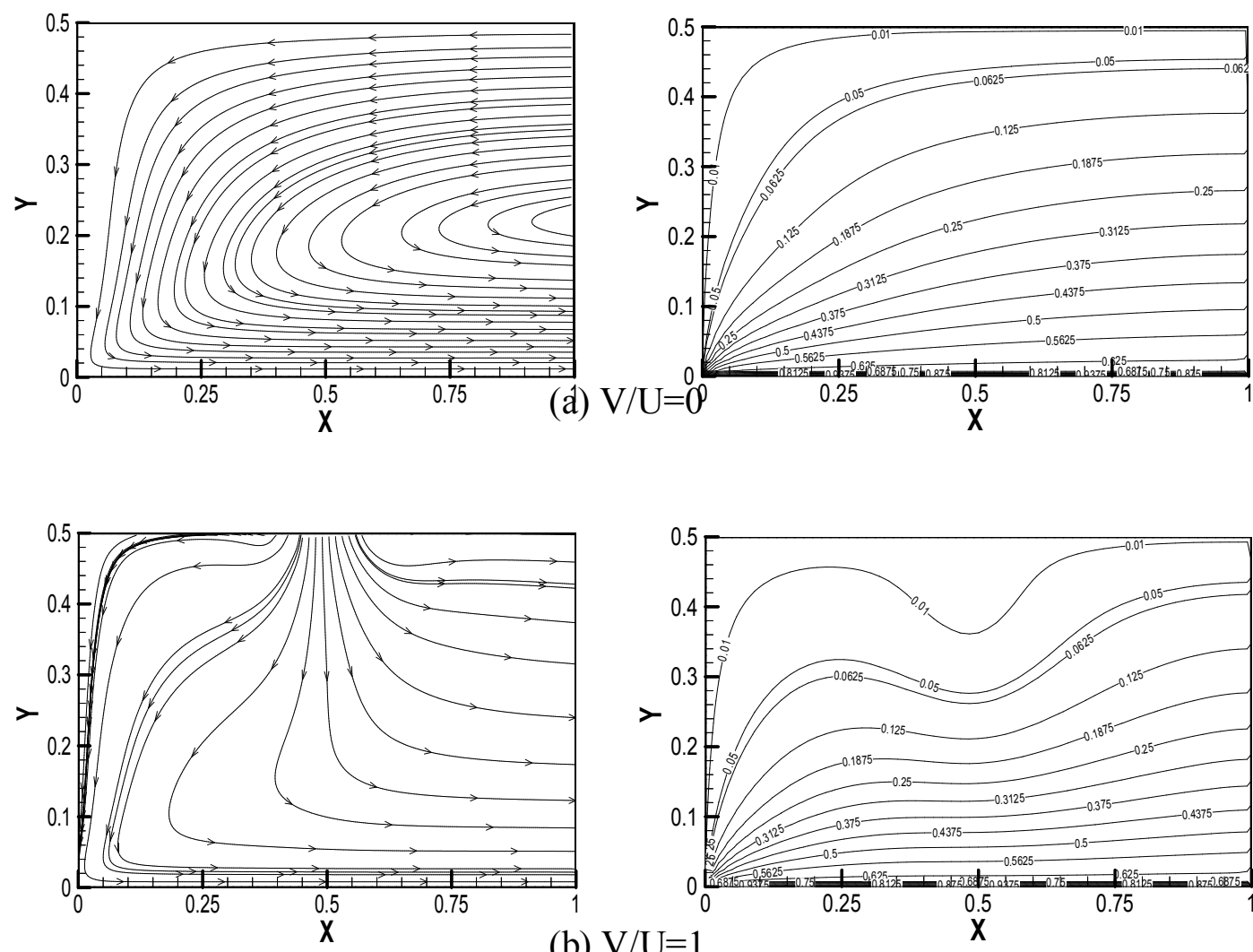

(b) $\mathrm{V} / \mathrm{U}=1$
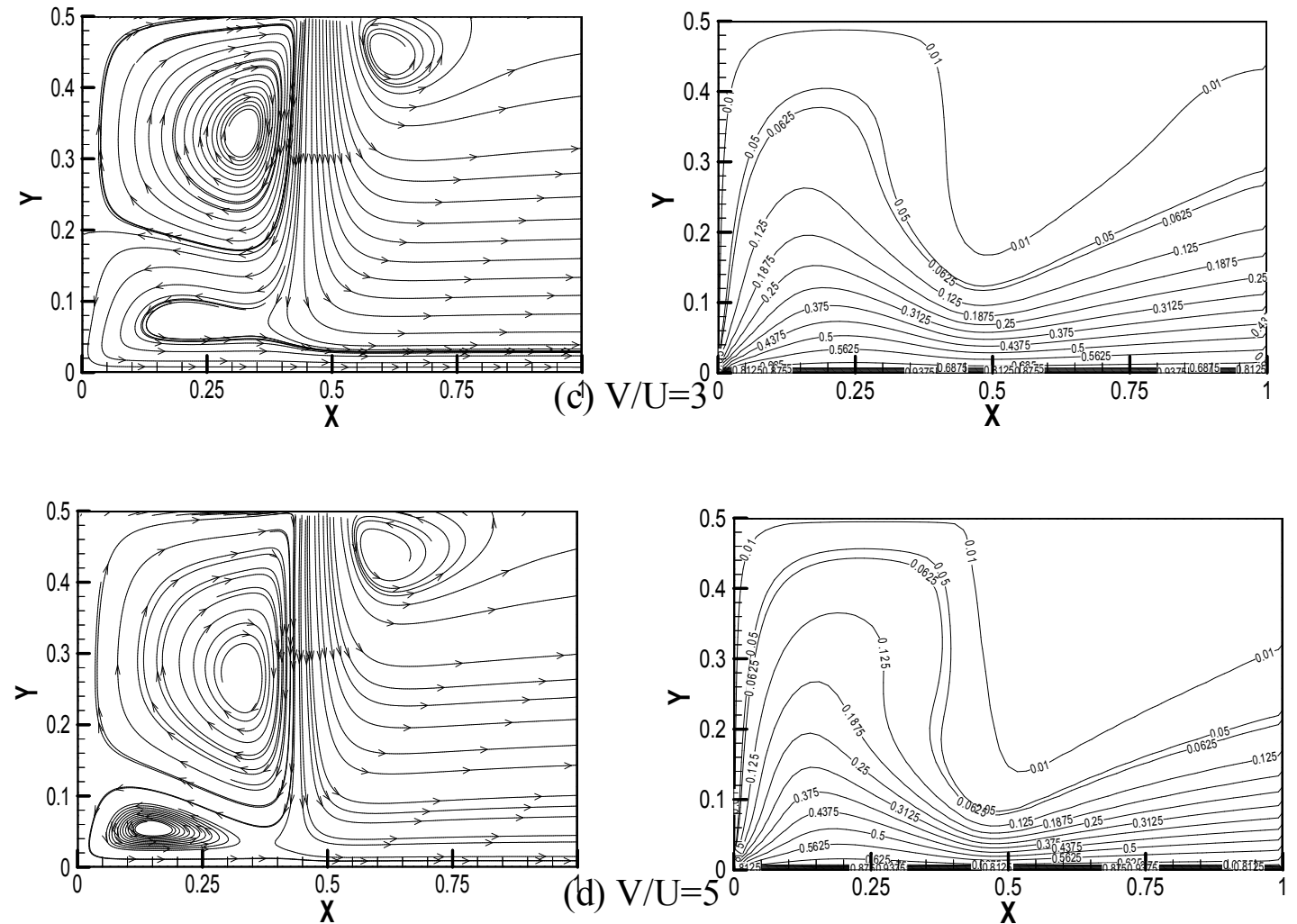

Figure (5) Streamlines (left), and Isotherms (right) contours at Different Jet Velocities for Reynolds Number $(\mathrm{Re}=100)$ 


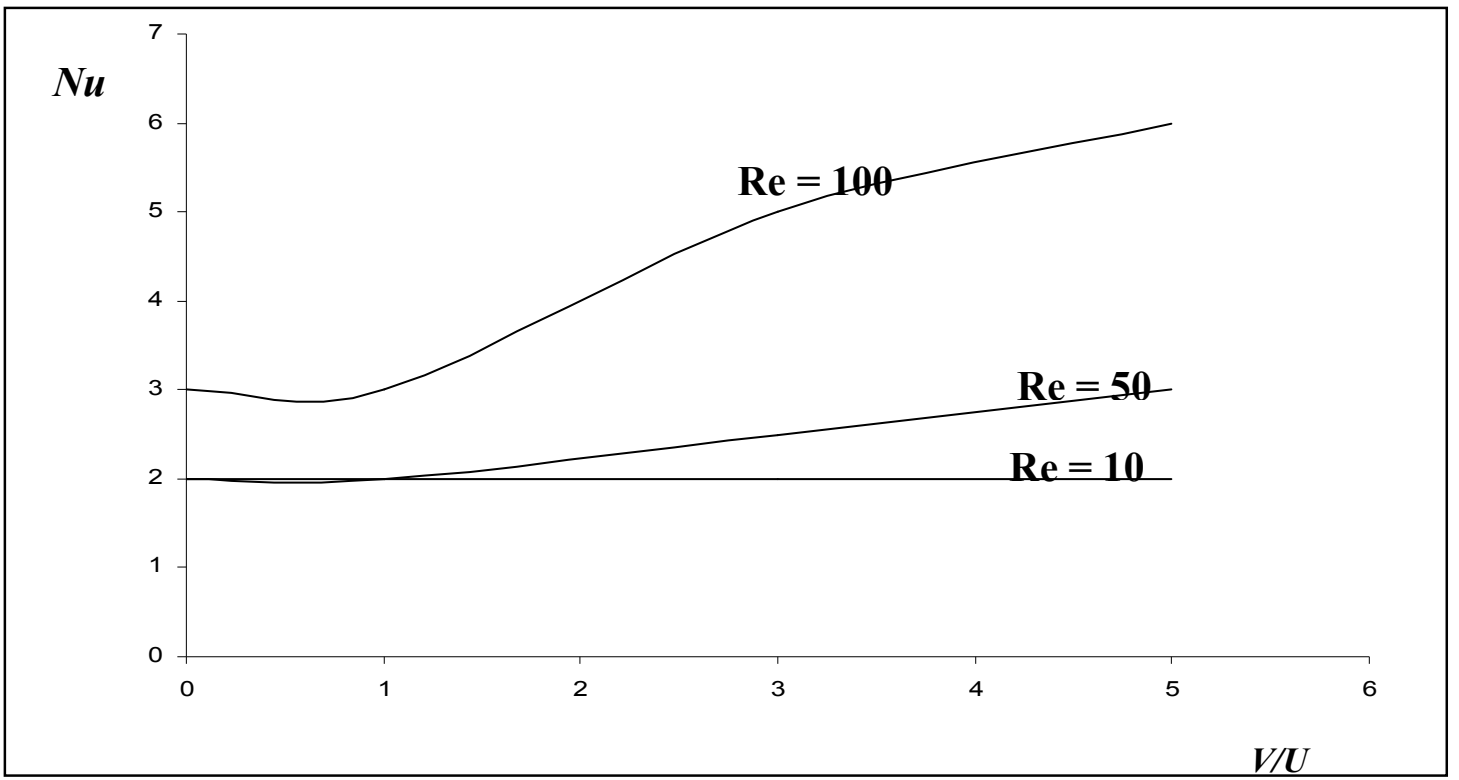

Figure (6) Average Nusselt Number with Jet Velocity at Different Reynolds number

\section{Conclusions}

The finite volume method with collocated grid is used to analyze the two dimensional steady flow and heat transfer over isothermal moving plate. The results show that at high jet velocity ratio $(\mathrm{V} / \mathrm{U}=5)$ and high Reynolds number $(\mathrm{Re}=100)$, the jet velocity causes high temperature gradient so that the heat transfer rate is doubled.

\section{References}

1- Altan, T., Oh, S., Gegel, H.,. Metal Forming Fundamentals and Applications. American Society of Metals, Metals Park, OH, 1979.

2- Fisher, E.G.,. Extrusion of Plastics. Wiley, New York, 1976.

3-Tadmor, Z., Klein, I.,. Engineering Principles of Plasticating Extrusion, Polymer Science and Engineering Series. Van Nostrand Reinhold, New York, 1970.

4-Karwe, M.V., Jaluria, Y.,. Fluid Flow and mixed convection transport from a moving plate in rolling and extrusion processes. ASME J. Heat Transfer, 1988, 110, 655-661.

5-Karwe, M.V., Jaluria, Y.,. Numerical simulation of thermal transport associated with a continuously moving at sheet in materials processing. ASME J. Heat Transfer ,1991,113, 612-619.

6-Kang, B.H., Jaluria, Y.,. Thermal modeling of the continuous casting process. J. Thermophysics Heat Transfer, 1993, 7 (1), 139-147.

7- Karwe, M.V., Jaluria, Y.,. Fluid Flow Phenomena in Materials Processing-The 2000 Freeman Scholar Lecture. ASME J. Fluid Engineering, 2001, Vol.123, 173-210.

8-Patankar, S.V., Numerical Heat Transfer and Fluid Flow, New York, Hemisphere Publishing Corporation, Taylor and Francis Group, 1980.

9- Rhie, C. M., and Chow, W. L., Numerical Study of the Turbulent Flow Past an Airfoil with Trailing Edge Separation, AIAA Journal, 1983,Vol.21, PP 1525-1532.

10- Sami, A., and Mohamed, E. A., The effect of extrusion slit on the flow and heat-transfer characteristics from a continuously moving material with suction or injection, International Journal of Heat and Fluid Flow, 2000, Vol.21 PP 84-91.

The work was carried out at the college of Engineering. University of Tikrit 